\title{
TEORIA DO DESENHO DE MECANISMOS: UMA PROPOSTA DE APLICAÇÃO AOS CONTRATOS INCOMPLETOS
}

\author{
MECHANISM DESIGN THEORY: A PROPOSAL OF \\ APPLICATION TO INCOMPLETE CONTRACTS \\ Lara Bonemer Rocha ${ }^{1}$ \\ PUC/PR \\ Marcia Carla Pereira Ribeiro ${ }^{2}$ \\ $\mathrm{PUC} / \mathrm{PR}$
}

\section{Resumo}

O artigo propõe a aplicação da teoria do desenho de mecanismos como uma forma de preencher as lacunas e as controvérsias decorrentes da incompletude dos contratos. $\mathrm{O}$ tema é contextualizado no âmbito da Nova Economia Institucional sob a ótica da teoria dos custos de transação. Parte-se da ideia de que ao celebrar um contrato, as partes visam a segurança jurídica, no sentido de tentar prever todas as circunstâncias possíveis. Contudo, a previsão ex ante é inviável, dada a complexidade das relações negociais, além da previsão de um máximo de situações possíveis tornar a redação do contrato excessivamente custosa, podendo até mesmo inviabilizar o negócio, o que torna os contratos, como regra, incompletos. Em consequência, o preenchimento destas lacunas contratuais e as controvérsias são levadas frequentemente para apreciação pelo Poder Judiciário, que em virtude da falta de previsibilidade de suas decisões, acaba por deixar as partes contratantes num potencial estado de insegurança jurídica. Conclui-se que a aplicação da teoria de desenho de mecanismos aos contratos incompletos, viabiliza uma solução das contingências mediante incentivos para que as partes adotem estratégias lícitas para alcançar resultados eficientes. Se desenhados incentivos fortes, os mecanismos se traduzem em normas autoaplicáveis, aptas a reduzir os custos de transação, até mesmo no âmbito do Poder Judiciário.

Palavras-Chave

Análise Econômica do Direito. Custos de Transação. Contratos. Teoria do desenho de mecanismos. Poder Judiciário.

\section{Abstract}

1 Doutoranda em Direito na PUC/PR (Bolsista CAPES). Mestre em Direito pela PUC/PR (Bolsista CNPQ). Editora-Geral da Revista de Direito Empresarial. Advogada.

2 Professora Doutora no PPGD/PUCPR e Professora Doutora no PPGD/UFPR. Estágio de Pós-doutorado pela FGVSP e pela Universidade de Lisboa. Pesquisa no âmbito da Chamada Pública no. 24/2012- Pesquisa Básica Aplicada da Fundação Araucária de Desenvolvimento Científico e Tecnológico do Paraná. 


\section{Revista da Faculdade Mineira de Direito $\mid$ v.20 N.40|216}

This article proposes the application of mechanism design theory as a way to fill the gaps in incomplete contracts. At first it is essential to contextualize the issue under the New Institutional Economics, as well as some considerations about the theory of transaction costs. It starts with the idea that when concluding a contract the parties seek legal certainty, trying to anticipate all possible bypotheses. However, this prediction ex ante is not feasible, given the complexity of business relationships. In addition, the forecast of a maximum possible situations makes the composion of the contract costly and may derail the deal. For these reasons the contracts are generally incomplete. Settled this premise, it is found that filling these gaps contract is taken for consideration by the Judiciary, which due to the lack of predictability of its decisions, leaves the contracting parties in a state of legal uncertainty. The proposal of this work is to apply the mechanism design theory to incomplete contracts, enabling a resolution of the contingencies in court by incentives for the parties to take legal strategies in order to achieve efficient results. If strong incentives are drown, mechanisms translate into self-enforcement norms, able to reduce transaction costs. To develop this work, it is used the theoretical tools of Economic Analysis of Law with a focus on institutional arrangements of the New Institutional Economics, more precisely, the transaction costs, incomplete contracts and the theory of mechanism design.

Keywords

Economic Analysis of Law. Transaction costs. Contracts. Mechanism design theory. Judiciary power.

\section{Introdução}

A interdisciplinaridade na pesquisa do Direito tem sido cada vez mais valorizada, na medida em que enriquece os trabalhos científicos, ao proporcionar ao pesquisador uma visão ampla do conteúdo que pretende abordar.

Neste contexto, a Análise Econômica do Direito- AED, como ferramental teórico de estudo, proporciona elementos aptos, por exemplo, à previsão dos efeitos das sanções legais sobre o comportamento humano, na medida em que permite prever como as pessoas reagem a incentivos.

No campo da AED, os primeiros conceitos utilizados pelos operadores do direito eram os da economia neoclássica. O desenvolvimento de estudos neste campo tornou evidente a necessidade de um aprimoramento desse instrumental, tornando-se indispensável a consideração de aspectos relacionados ao comportamento para uma formulação correta de hipóteses.

Os agentes agem de acordo com seu auto-interesse, porém, sujeitos a uma racionalidade limitada. Além disso, os incentivos são 


\section{Revista da Faculdade Mineira de Direito $\mid$ v.20 N.40 $\mid 217$}

capazes de moldar a conduta dos indivíduos, a fim de que interajam de forma a alocar de forma mais eficiente os recursos escassos.

Ao celebrar um contrato, as partes tendem a buscar, no estado inicial, o máximo de certeza possível quando ao seu integral cumprimento. Pretendem, a formulação de um contrato completo. Contudo, a completude contratual não se coaduna com a realidade, dada a impossibilidade de previsão, pelas partes, no momento da fixação do contrato, prever todos os acontecimentos potenciais para o futuro. Há também a possibilidade de que seja de interesse das partes que haja algumas lacunas, pois o cumprimento da avença pode estar ao final vinculado a fato futuro ou incerto, ou para que não seja superada de forma integral a assimetria informacional que garante uma situação favorável a uma das partes.

Desta forma, caso fosse possível, os custos de transação incidentes sobre os contratos completos poderiam inviabilizar sua celebração, seja pelo custo de prever o máximo de eventualidades possíveis, seja pelo risco expost de vincular o cumprimento da avença a fato futuro, o que faz com que os contratos mantenham-se, como regra, incompletos.

O problema estará no momento em que as partes se deparam com o preenchimento das lacunas contratuais. $\mathrm{Na}$ busca pela melhor estratégia para proceder neste caso, a definição de a quem delegar eventual decisão, de forma a assegurar a alocação mais eficiente dos recursos envolvidos.

O objetivo do artigo é enfrentar estas situações.

Num primeiro momento será contextualizado o estudo no âmbito da Nova Economia Institucional para, na sequência, tratar da teoria dos custos de transação em Oliver Williamson.

Assentadas as bases, será analisada a teoria dos contratos incompletos e averiguado como tem sido feito o preenchimento destes vazios contratuais no Brasil para, ao final, tratar-se da aplicação da teoria do desenho de mecanismos como uma possível resolução dos problemas apontados.

\section{A Nova Economia Institucional}




\section{Revista da Faculdade Mineira de Direito $\mid$ v.20 N.40|218}

A Nova Economia Institucional (NEI) é uma iniciativa interdisciplinar que busca conjugar contribuições de Economia, Direito, teoria das organizações, Ciência Política, Sociologia e Antropologia para compreender o funcionamento das instituições ${ }^{3}$ sociais, políticas e sociais, assim como seu surgimento, seus propósitos, e como se transformam no curso do tempo. ${ }^{4}$

A terminologia NEI aparece em Oliver Williamson, no ano de 1975, em seu estudo sobre os custos de transação, influenciado pelas publicações de Ronald Coase em 1937 - sobre a análise da firma- , de Hayek em 1937 e 1945 - sobre as limitações ao conhecimento dos fatos econômicos-, e ainda, de Simon (1947), Arrow (1963), Davis e Douglass North (1971), Alchian e Demsetz (1972) e outros. ${ }^{5}$ A NEI também reúne trabalhos de Coase, com o estudo sobre o custo social ${ }^{6}$ e de North ${ }^{7}$, com o notável trabalho sobre instituições.

Peter Klein afirma que a NEI evita o holismo da escola antiga, na medida em que segue o individualismo metodológico estrito, sempre calçando suas explicações em termos de objetivos, planos e ações dos indivíduos ${ }^{8}$ Diferencia-se da escola neoclássica que insiste em que as análises políticas sejam guiadas pelo que Coase denomina de análise comparativa das instituições ${ }^{9}$, em que as comparações são feitas no âmbito do

\footnotetext{
3KLEIN, Peter G. New Institucional Economics. Department of Economics, University of Georgia, 1999, p. 456.

4NORTH, Douglass C. Economic Performance Through Time. Nobelprize.org. Nobel Media AB 2014. Web. 11 Oct. 2014. Disponível em:

<http://www.nobelprize.org/nobel_prizes/economic-sciences/laureates/1993/northlecture.html>. Acesso em: 15 jul. 2016.

5KLEIN, Peter G. New Institucional Economics, p. 457.

6COASE, Ronald. H. O problema do custo social. In: The Latin American and
}

Caribbean Journal of Legal Studies, Vol. 3, Issue 1, Article 9, University of Chicago, 2008, p. 1-35.

7NORTH, Douglass C. Economic Performance Through Time. Nobelprize.org. Nobel Media AB 2014. Web. 11 Oct. 2014. Disponível em:

<http://www.nobelprize.org/nobel_prizes/economic-sciences/laureates/1993/northlecture.html>. Acesso em: 15 jul. 2016.

8KLEIN, Peter G. New Institucional Economics, p. 458.

9COASE, Ronald H. (1964), 'The Regulated Industries: Discussion', 54 American

Economic Review, 194-197, p. 195. 


\section{Revista da Faculdade Mineira de Direito $\mid$ v.20 N.40 219}

mercado. Para Coase, a análise de um sistema hipotético pode prover técnicas de análise que não seriam passíveis de aplicação no plano real. É preciso pensar arranjos alternativos que funcionariam na prática. ${ }^{10}$

Para organizar os vários ramos da NEI, Davis e North ${ }^{11}$ apresentam uma distinção entre ambiente institucional e arranjos institucionais. O ambiente institucional é formado pelas regras do jogo, que se apresentam como guias do comportamento individual. Podem ser formais, traduzidas em regras explícitas, como, por exemplo, a Constituição, as leis e os direitos de propriedade, e informais, consideradas as regras implícitas, como é o caso das convenções sociais. ${ }^{12}$

Os arranjos institucionais, por sua vez, são guias específicos que Williamson denomina estruturas de governança, estabelecidas entre as partes em uma transação para regular as negociações. Empresas, contratos de longo-termo, burocracia pública, organizações não lucrativas e outros acordos contratuais são exemplos de arranjos institucionais. ${ }^{13}$

O presente estudo é voltado ao ramo da NEI concernente aos arranjos institucionais, mediante a análise dos custos de transação e da teoria do desenho de mecanismos aplicado aos contratos incompletos. Nesse contexto, aborda-se a noção de custos transacionais.

\section{Os custos de transação}

A análise dos custos de transação tem seu marco inicial em Coase, no artigo intitulado "O problema do custo social", escrito em 1960, em que aborda, dentre outros aspectos, as ações das business firms que geram efeitos prejudiciais a terceiros. ${ }^{14}$

10KLEIN, Peter G. New Institucional Economics, p. 458.

11DAVIS, Lance E.; NORTH, Douglass C. (1971), Institutional Change and

American Economic Growth, Cambridge, Cambridge University Press.

12NORTH, Douglass C. Economic Performance Through Time. Acesso em: 15 jul. 2016.

13DAVIS, Lance E.; NORTH, Douglass C. (1971), Institutional Change and American Economic Growth.

14COASE, Ronald. H. O problema do custo social. In: The Latin American and Caribbean Journal of Legal Studies, Vol. 3, Issue 1, Article 9, University of Chicago, 2008p. 1-35. 


\section{Revista da Faculdade Mineira de Direito $\mid$ v.20 N.40|220}

Coase analisa inicialmente problemas em que as transações de mercado se operam sem custos. Reconhece, contudo, que esta é uma suposição bastante irrealista, já que há custos pré e pós as transações de mercado, como por exemplo, a busca por informações sobre as partes negociantes, a elaboração dos termos da negociação e a previsão das hipóteses de descumprimento e de suas consequências. Os custos podem, inclusive, evitar a ocorrência de algumas transações que seriam lavadas a cabo em uma realidade em que o sistema de preços funcionasse sem custos. $^{15}$

Quando as fricções das transações de mercado são levadas em conta, a realocação de direitos ocorrerá somente quando o aumento no valor da produção por ela gerado for maior aos custos incorridos para implementá-la. Nessas condições, Coase pontua que a delimitação inicial dos direitos exerce influência sobre a eficiência com a qual o sistema de preços opera. $^{16}$

A partir de 1971, Williamson, baseando-se nos trabalhos de Coase e de Arrow, iniciou os primeiros estudos com o objetivo de generalizar a abordagem sobre o problema dos custos de transação no contexto dos mercados e hierarquias. Em 1985, Williamson publica o livro "The economic institutions of capitalism", que dedica o primeiro capítulo à análise dos custos de transação na economia. ${ }^{17}$

A economia dos custos de transação, segundo Williamson, é parte da tradição das pesquisas desenvolvidas no âmbito da NEI. O autor dedica especial enfoque às instituições econômicas do capitalismo, com ênfase nas firmas, nos mercados e nas relações contratuais. Defende que as instituições econômicas do capitalismo têm como principal propósito e efeito reduzir os custos de transação. ${ }^{18}$

Williamson compara os custos de transação às fricções ou atritos existentes nos sistemas físicos. ${ }^{19}$ Devem ser compreendidos como todas as

15COASE, Ronald. H. O problema do custo social, p. 12.

16Idem., p. 13.

17WILLIAMSON, Oliver E. The Economic Institutions of Capitalism. New York:

The Free Press, 1985, p. 14.

18Idem., p. 16.

19Idem., p. 19. 


\section{Revista da Faculdade Mineira de Direito $\mid$ v.20 N.40|221}

barreiras impostas às partes no ato de instalação das relações contratuais firmadas no âmbito do mercado. ${ }^{20}$

São elementos que impedem que determinado movimento ocorra sem qualquer resistência e, a depender do tamanho da resistência, podem, inclusive, impedir sua correta execução ou inviabilizá-la.

A economia dos custos de transação propõe a análise do problema da organização econômica como um problema relacionado ao contrato em que se analisa os custos pré e pós contratação.

\subsection{Custos ex ante}

Os custos ex ante são os custos de negociação prévios à celebração do contrato. Envolvem a pesquisa a respeito da viabilidade do negócio e das partes contratantes, no que se refere à sua capacidade de cumprir contratos. Além disso, abrangem a barganha e a redação do contrato, com a previsão das formas de descumprimento e suas respectivas regulamentações. ${ }^{21}$

Segundo Rachel Sztajn ${ }^{22}$

são o esforço na procura de bens em mercados, a análise comparativa de preço e qualidade antes de tomar a decisão, o desenho da garantia quanto ao cumprimento das obrigações pela outra parte, a certeza do adimplemento, seguro e a tempo [...].

Ao celebrar um contrato, as partes visam, como regra, seu cumprimento. Para tanto, buscam estabelecer ex ante todas as contingências possíveis e as soluções adequadas, a fim de que se tenha previsibilidade e, via de consequência, segurança.

20CAMINHA, Uinie; LIMA, Juliana Cardoso. Contrato Incompleto: uma perspectiva entre direito e economia para contratos de longo termo. Revista Direito GV. São Paulo 10 (1), p. 155-200, Jn-jun. 2014, p. 160.

21WILLIAMSON, Oliver E. The Economic Institutions of Capitalism, p. 17. 22SZTAJN, Rachel. Supply chain e incompletude contratual. Disponível em: <http://www.revistassystemas.com.br/index.php/systemas/article/viewPDFInterstitial/ 10/11>. Acesso em: 01 ago.2016. 


\section{Revista da Faculdade Mineira de Direito $\mid$ v.20 N.40|222}

Cooter e Ullen denominam essa antecipação como "riscos ex ante", na medida em que designam o risco de prejuízos futuros com que as partes se defrontam ao negociar um contrato. $O$ exemplo analisado pelos autores é o de uma família que assina um contrato com uma Construtora para a construção de uma casa. A planta baixa, os materiais de construção, o estilo dos carpetes, o paisagismo, bem como o preço a ser pago e a data para a entrega da obra. ${ }^{23}$

Traçadas estas obrigações, as partes designam as penalidades na hipótese de eventual descumprimento. Contudo, acontecimentos não previstos podem ocorrer, como por exemplo, uma greve dos fornecedores de madeira, uma guerra no país fabricante dos tubos necessários à construção, problemas burocráticos para a aprovação da obra, ou ainda, o desinteresse da família em concluir a casa ou até mesmo a falta de condições financeiras para o adimplemento do acordado.

Estas imprevisões são denominadas "prejuízos ex post", que serão objeto de análise do próximo item.

\subsection{Custos ex post}

Os custos ex post se configuram após a contratação. Podem assumir diversas formas, como, por exemplo, os custos da má adaptação, incorrido quando as transações saem do alinhamento em relação a curva de contrato em deslocamento; os custos de barganha incorridos quando se fazem esforços bilaterais para corrigir os erros; os custos de instalação e funcionamento associados a estruturas de governança para que se recorra em caso de litígios; os custos de criação de vínculos para efetuar compromissos seguros.

Estão relacionados ao inadimplemento ou adimplemento imperfeito da parte adversa. Envolvem, segundo Sztajn ${ }^{24}$, a redação de instrumentos contratuais que reflitam as tratativas entre contratantes e disponham sobre direitos, deveres e obrigações, incluindo as relacionadas

23COOTER, Robert; ULLEN, Thomas. Direito e Economia. Tradução Luis Marcos Sander e Francisco Araújo Costa. 5. ed. Porto Alegre: Bookman, 2010. p. 222. 24SZTAJN, Rachel. Supply chain e incompletude contratual. Acesso em: 01 ago.2016. 


\section{Revista da Faculdade Mineira de Direito $\mid$ v.20 N.40|223}

a eventual inadimplemento, como o custo de demandar em juízo ou qualquer outra forma de solução de controvérsias.

Além disso, conforme destacam Uinie Caminha e Juliana Lima ${ }^{25}$ :

deve-se mencionar que os custos de transação não dependem apenas das características do acordo firmado, pois, também são resultantes das condutas das partes, em especial, quando se comportam com racionalidade limitada e oportunismo, bem como de condições objetivas, como as incertezas das transações decorrentes das mudanças sociais, a duração e os investimentos específicos do contrato, fatores inerentes às relações contratuais de longo prazo [...].

Os custos de transação ex post estão relacionados não somente aos custos de disciplina das contingências passíveis de se configurarem durante a relação negocial, como também se condicionam à assimetria informacional e à racionalidade limitada dos agentes contratantes.

Ao assinar um contrato, as partes precisam optar entre alocar riscos ex ante e prejuízos ex post. Ao negociar condições explícitas para alocar riscos, arcarão com os custos de transação ex ante. Se deixarem uma lacuna, arcarão com os custos de transação ex post. É preciso ponderar se em dada situação os custos de alocar riscos ex ante é inferior ao benefício da negociação.

Se o custo de alocação de um risco é superior ao custo de alocação de um prejuízo torna-se vantajoso deixar a lacuna. De outro lado, se o custo de alocação de um risco é inferior ao custo de alocação de um prejuízo, é interessante para as partes que a lacuna seja preenchida. ${ }^{26}$

\section{Os contratos incompletos}

Ao celebrar uma negociação, as partes contratantes tendem a buscar contratos completos. Por contrato, entende-se uma promessa juridicamente vinculante de agir no futuro, como por exemplo a promessa 


\section{Revista da Faculdade Mineira de Direito $\mid$ v.20 N.40 224}

de entrega de determinada mercadoria em uma determinada data, em troca da promessa de pagamento de certa quantia, também em data futura. ${ }^{27}$

A residência ou o estabelecimento comercial das partes contratantes em locais diferentes, a contratação de prestações continuadas à longo prazo, de empréstimos para atingir o objetivo do contrato, a partilha de riscos e os investimentos antecipados com objetivo de lucro, são razões pelas quais as partes buscam a celebração de um contrato.

A completude, neste aspecto, tem como objetivo garantir às partes contratantes a antecipação dos efeitos dos comportamentos desviantes e as suas contrapartidas. Assim, as hipóteses de descumprimento contratual são previamente reguladas pelo contrato a fim de que as partes sejam incentivadas, mediante a aplicação de sanções, a cumprir o estabelecido.

Contudo, o contrato completo pode ser considerado impossível ${ }^{28}$, dada a impossibilidade de antever todas as contingências passíveis de se configurar durante a relação contratual. Mesmo nos contratos de curta duração que disciplinem trocas simples, a interação entre as partes é dotada de certa imprevisibilidade, haja vista os acontecimentos decorrentes de caso fortuito e força maior. Outro fator que impede a perfeita previsibilidade decorre do fato dos agentes poderem interagir entre eles e até mesmo com o ambiente, modificando a situação futura. Logo, mesmo que o contrato pudesse teoricamente prever todas as situações, as interações podem proporcionar eventos diversos.

Por outro lado, o custo de informação para prever-se o máximo de contingências possíveis poderia inviabilizar ex ante a realização do negócio. Neste sentido, Bellantuono afirma que "nenhum contrato estabelece uma disciplina específica para todos os eventos que poderiam interferir na

\footnotetext{
27SCOTT, Robert E. TRIANTIS, George G. Incomplete Contracts and the Theory of Contract Design, 56 Case Western Reserve Law Review. 187 (2005) Disponível em: http://scholarlycommons.law.case.edu/caselrev/vol56/iss1/9 Acesso em 15 jul. 2016, p. 188.

28 "[...] "é impossível pressupor todos os acontecimentos ou eventos que poderão ter lugar entre os seres humanos, em especial no futuro" [...] PINHEIRO, Armando Castelar; SADDI, Jairo. Direito, economia e mercados. Rio de Janeiro: Elsevier, 2005, p. 117.
} 


\section{Revista da Faculdade Mineira de Direito $\mid$ v.20 N.40|225}

execução das obrigações". ${ }^{29}$ E mesmo que isso fosse possível, Caminha e Lima ponderam que "especificar todas as possíveis contingências seria uma atividade custosa e, mesmo assim, sujeita à condições de incerteza.". ${ }^{30}$ As autoras afirmam que o custo de transação é o elemento que a Escola de Chicago identifica como responsável pela incompletude dos contratos

podendo se apresentar em razão da racionalidade limitada das partes, principalmente quando os contraentes estão diante de decisões complexas, já que nem sempre os indivíduos possuirão todas as informações necessárias para se alcançar a decisão "ótima", bem como em virtude da assimetria de informação, da conduta oportunista, dentre outros fatores. ${ }^{31}$

Ademais, o contrato completo nem sempre é desejável. Sob a perspectiva econômica, o contrato eficiente não é, necessariamente, o mais completo possível. A flexibilidade contratual pode ser um fator conducente à eficiência almejada pelas partes.

Tome-se como exemplo os chamados pelos economistas de specific investments, também conhecido pelos advogados como reliance expenditures. Nestas formas de contratação o objetivo é o de que os recursos investidos pelas partes resultem em um ganho superior àquele que seria obtido se os investimentos forem inseridos em outra negociação. O nível ótimo de eficiência do contrato é atingido quando, ao final, é verificado o ganho. ${ }^{32}$

Compromissos contratuais que motivam investimentos eficientes ex ante podem frustrar a eficiência das trocas compelindo os agentes à cumpri-la quando, por circunstâncias não previstas no contrato, não há ganhos ao final. $\mathrm{O}$ contrato pode comprometer as partes à realizar trocas que podem se tornar ineficientes ao final, de modo que o custo de investimento supera o a renda da promessa.

29BELlantUONO, Giuseppe. Analisi economica del diritto. Trento: Uni-service, 2005, p. 61.

30CAMINHA, Uinie; LIMA, Juliana Cardoso. Contrato Incompleto, p. 157.

31Idem., p. 163.

32SCOTT, Robert E. TRIANTIS, George G. Incomplete Contracts and the Theory of Contract Design, p. 189. 


\section{Revista da Faculdade Mineira de Direito $\mid$ v.20 N.40|226}

Para evitar este problema, na celebração do contrato as partes precisam buscar garantir que a troca ocorrerá apenas nas circunstâncias em que produza rendimentos. Como, então, garantir este objetivo? A teoria dos contratos incompletos vem justamente para responder à esta questão. Havendo incerteza quanto ao resultado quando da elaboração do contrato, é de interesse das partes que o instrumento seja dotado de flexibilidade para evitar trocas ineficientes. ${ }^{33}$

Nesta hipótese, a incompletude do contrato torna-se um ato intencional dos contraentes, podendo funcionar como estratégia contratual. Fernando Araújo considera esta incompletude como um inacabamento deliberado ou estratégico, em que se visa alcançar um nível ótimo de cumprimento ou ainda, em que se visa maliciosamente deixar interstícios no contrato para serem explorados expost. ${ }^{34}$

Sztajn ${ }^{35}$ associa os contratos incompletos à "capacidade limitada de se descrever os infinitos estados da natureza, predispor medidas para execução da operação, se ou quando, sofrerem alterações". E traz como exemplo as operações de comércio internacional, em que há vazios, ambiguidades ou lacunas no clausulado negocial, quando o idioma pode constituir barreira para a exata compreensão do regramento. Trata-se, na hipótese, de uma incompletude que existe independentemente da vontade das partes, decorrente da complexidade da tratativa. ${ }^{36}$

Robert Scott e George Triantis afirmam que a incompletude dos contratos possui significados diferentes para os economistas e para os advogados. Para estes, o contrato é incompleto quando falha no seu mister de descrever obrigações que devem ser cumpridas pelas partes em determinadas circunstâncias. Para os economistas, por outro lado, o

33SCOTT, Robert E. TRIANTIS, George G. Incomplete Contracts and the Theory of Contract Design, p. 189.

34ARAÚJO, Fernando. Teoria econômica do contrato. Coimbra: Almedina, 2007, p. 156.

35SZTAJN, Rachel. Supply chain e incompletude contratual. Acesso em: 01 ago.2016.

36PINHEIRO, Armando Castelar. Segurança jurídica, crescimento e exportações. Disponível em: <www.ipea.gov.br/pub/td/2005/td_1125.pdf>. Acesso em: 30 jul. 2016. 


\section{Revista da Faculdade Mineira de Direito $\mid$ v.20 N.40|227}

contrato é incompleto quando falha em promover eficiência. São considerados incompletos no sentido informacional, porém completos no que se refere às obrigações: o cumprimento ocorrerá apenas quando o resultado for eficiente. ${ }^{37}$

Neste sentido, Marasco pondera que se é a intenção dos agentes evitar, desde o início, o risco superveniente capaz de alterar o equilíbrio econômico do contrato, é preferível que a tratativa seja aberta, pela qual a contraprestação, ao invés de ser determinada ex ante é calculada conforme a apuração das despesas efetivamente suportadas na execução da prestação. $^{38}$

A análise econômica deve, segundo Sztajn e Zylbersztajn, "considerar o ambiente normativo no qual os agentes atuam, para não correr o risco de chegar a conclusões equivocadas ou imprecisas, por desconsiderar os constrangimentos impostos pelo Direito ao comportamento dos agentes econômicos". ${ }^{39}$

É preciso compreender que as relações negociais são levadas a efeito em sistemas dinâmicos que podem se tornar complexos na medida em que ocorre a interação entre os agentes. A economia, segundo Beinhocker, é um sistema não linear, haja vista que de um único fato podem derivar uma série de comportamentos e um único ajuste em um deles altera toda a cadeia de eventos. ${ }^{40}$

A teoria dos contratos incompletos tem maior aplicabilidade nos contratos de longa duração ou de execução diferida, em que a negociação é considerada complexa pois relacionada a fatores como racionalidade limitada das partes, comportamento oportunista, e incertezas dos negócios

37SCOTT, Robert E. TRIANTIS, George G., Incomplete Contracts and the Theory of Contract Design, p. 190.

38MARASCO, Gherardo. La rinegoziazione del contratto - Strumenti legali e convenzionale a tutela dell'equilibrio negoziale. [S. 1.]: Cedam, 2006, p. 16.

39SZTAJN, Rachel; ZYLBERSZTAJN, Decio. Direito e economia: análise econômica do direito e das organizações. Rio de Janeiro: Campus, 2005, p. 3.

40BEINHOCKER, Eric D. The Origin of Wealth. Evolution, complexity, and the radical remaking of economics. Harvard Business School Press, Boston, Massachussets, 2006, p. 105. 


\section{Revista da Faculdade Mineira de Direito $\mid$ v.20 N.40|228}

jurídicos. Vale dizer, em contratos simples e de curto prazo, não é interessante a flexibilidade contratual.

Torna-se oportuno, neste momento, questionar qual deve ser a solução, ex post, para as situações de descumprimento nos contratos incompletos.

Cooter e Ullen afirmam que os tribunais se deparam com estas perguntas ao decidir disputas contratuais e os legisladores ao fazerem as leis que regulam os contratos e que cabe a teoria do direito contratual a orientação dos tribunais, legisladores e partes privadas que os celebram. ${ }^{41}$ Os Autores ponderam que os tribunais precisam de regras para preencher lacunas em contratos e que cabe ao direito minimizar os custos de transação da negociação de contratos fornecendo condições e regulamentações supletivas eficientes. ${ }^{42}$

A ideia é a de que as partes contratantes tenham a tranquilidade de, havendo uma situação imprevista, os tribunais terem condições de suprir a lacuna contratual com a alocação eficiente dos recursos.

Contudo, não é o que ocorre na prática do Poder Judiciário brasileiro, conforme será abordado no item seguinte.

\subsection{O preenchimento das lacunas contratuais no Brasil}

Os contratos celebrados no âmbito empresarial no Brasil muito comumente delegam ao Poder Judiciário a competência para resolver eventuais controvérsias surgidas durante a vigência do contrato. É muito comum que contenham, em suas últimas cláusulas, a eleição de foro judicial para fins de submissão de conflitos.

Em meados da década de 1990, com o desenvolvimento de estudos a respeito da arbitragem e, mormente após 1996, com a entrada em vigor da Lei n. 9.307/1006, a arbitragem ganhou espaço como ferramenta de solução alternativa de conflitos empresariais.

A incompletude contratual, quando não tenha sido resolvida pela barganha entre as partes, seja decorrente ou não da intenção das partes,

41COOTER, Robert; ULLEN, Thomas. Direito e Economia, p. 224.

42Idem, p. 225. 


\section{Revista da Faculdade Mineira de Direito | v.20 N.40|229}

resulta na análise do caso pelo Poder Judiciário ou pelas Câmaras de Arbitragem para dirimir a controvérsia. Neste artigo optou-se por um especial enfoque quanto ao papel desempenhado pelo Poder Judiciário.

O Brasil se caracteriza por um alto índice de instabilidade nas decisões judiciais que afeta substancialmente a segurança dos agentes ao contratar. Em estudo realizado sobre a falta de previsibilidade do Poder Judiciário, foi constatado que

A falta de prevalência da jurisprudência dos Tribunais Superiores e dos Estados, bem como por parte dos juízes de primeira instância e a divergência de posicionamento entre magistrados de um mesmo órgão ou entre órgãos de uma mesma hierarquia, assim como a repentina mudança de entendimento jurisprudencial e ainda, a criação jurisprudencial do direito, conduzem a um cenário indesejável, que prejudica as transações econômicas. Sem que os agentes tenham condições de antever os efeitos de suas condutas no plano judicial, as transações ficam mais arriscadas, introduzindo o aumento dos custos de transação, e seus impactos na fixação dos preços. ${ }^{43}$

A previsibilidade do Direito e, em especial, das decisões judiciais estimula os indivíduos a empenharem novas formas de atividade econômica, na medida em que os frutos dessa atividade serão protegidos. A ineficiência, de outro lado, reflete não apenas em injustiça, mas também no desempenho econômico, com a elevação dos custos e seu impacto pode ser verificado no progresso tecnológico e nos investimentos empresariais. $^{44}$

No mesmo sentido, Christiane Rezende e Décio Zylbersztajn ${ }^{45}$ em estudo sobre as decisões judiciais proferidas nos casos de quebras dos

43ROCHA, Lara Bonemer Azevedo da. O desenvolvimento pelo acesso à justiça. São Paulo: Boreal, 2015, p. 02.

44ROCHA, Lara Bonemer Azevedo da. O desenvolvimento pelo acesso à justiça, p. 23.

45REZENDE, Christiane Leles Rezende; ZYLBERSZTAJN, Decio. Quebras contratuais e dispersão de sentenças. Revista Direito GV. São Paulo 7 (1), p. 155-176, Jan-Jul 2011, 173-174. 


\section{Revista da Faculdade Mineira de Direito $\mid$ v.20 N.40|230}

contratos de soja verde constatou que "a forma pela qual a quebra de contratos é decidida nos tribunais gera impactos nas estratégias das organizações", e concluiu que "o estudo dá transparência ao fato de que o Judiciário influencia o ambiente de negócios, pois as suas decisões produzem efeitos que repercutem nas ações dos agentes privados".

Neste cenário

as empresas ficam receosas de negociar, uma vez que não puderam contar com a segurança jurídica de que o contrato seria cumprido. A falta de consideração dos efeitos econômicos de segunda ordem pode ser interpretada como 'miopia econômica' do Judiciário.

Se o Poder Judiciário, responsável por preencher as lacunas contratuais dos clausulados complexos e garantir o cumprimento do que foi pactuado não transmite a necessária segurança jurídica às partes contratantes, dada sua imprevisibilidade, ainda permanece um dúvida quanto à melhor estratégia para garantir-se o cumprimento do contrato de forma eficiente.

Robert Scott e George Triantis, ao analisarem os contratos incompletos, sugerem que a economia dos contratos deveria incorporar um entendimento mais concreto a respeito do processo judicial para o enforcement dos contratos. Propõem, para tanto, uma ligação entre enforcement judicial e a teoria do desenho de mecanismos. ${ }^{46}$

Para que se possa compreender a proposta dos autores é preciso, em um primeiro momento, apresentar a teoria do desenho de mecanismos para que, na sequência, possa ser sondada para aplicação perante o Poder Judiciário.

\section{A teoria do desenho de mecanismos}

46SCOTT, Robert E. TRIANTIS, George G., Incomplete Contracts and the Theory of Contract Design, p. 190. 


\section{Revista da Faculdade Mineira de Direito $\mid$ v.20 N.40 231}

No ano de 2007, Leonid Hurwicz, Eric S. Maskin e Roger B. Myerson receberam o prêmio Nobel de Economia pela criação da teoria do desenho de mecanismos e sua aplicação no cenário econômico.

Os autores perceberam que a análise econômica fundada apenas na matemática era insuficiente para explicar os problemas relacionados à alocação eficiente de recursos. A partir dos estudos realizados por Cournot em 1938, os teóricos da economia começaram a analisar as decisões dos indivíduos como ferramentas importantes para compreender o abastecimento e a demanda na teoria dos preços. ${ }^{47}$

$\mathrm{Na}$ primeira metade do século vinte alguns matemáticos formularam modelos para analisar decisões racionais competitivas em um contexto geral, fundando as bases da teoria dos jogos, a partir dos estudos de Borel em 1921, von Neumann em 1928, von Neumann e Morgenstern em 1944, Nash em 1951 e Myerson em 1999. ${ }^{48}$

O debate entre capitalismo e socialismo exigiu um ferramental além da teoria dos preços. Esta poderia demonstrar, sob certas circunstâncias, que mercados livres poderiam atingir eficiência alocativa, mas estes resultados não tinham o condão de provar que o comando socialista da economia não teria a possibilidade de produzir resultado equivalente. ${ }^{49}$

Para permitir uma comparação analítica sobre diferentes formas de organização econômica, foi necessário uma nova e mais geral teoria. Neste contexto, Hayek em 1945, afirmou que a chave para sua nova teoria econômica seria o reconhecimento de que as instituições econômicas de todos os tipos devem servir para a função essencial de compreender toda a informação disponível a respeito dos desejos e dos recursos de diferentes indivíduos na sociedade. Vale dizer, diferentes instituições econômicas deveriam ser comparadas a mecanismos de comunicação. ${ }^{50}$

\footnotetext{
47MYERSON, Roger B - Prize Lecture: Perspectives on Mechanism Design in Economic Theory". Nobelprize.org. Nobel Media AB 2014. Web. 3 Aug 2016.

$<$ http://www.nobelprize.org/nobel_prizes/economicsciences/laureates/2007/myerson-lecture.html>, p. 320 .

48Idem.

49Idem, p. 321.

50Idem.
} 


\section{Revista da Faculdade Mineira de Direito | v.20 N.40|232}

Hayek acusou também os economistas matemáticos de sua época de não perceberam a importância da dinâmica do sistema dos mercados. Em seu discurso no dia em que recebeu o Prêmio Nobel de Economia, em 11 de dezembro de 1974, Hayek reafirmou o caráter complexo da economia. Para o autor, é preciso compreender que os aspectos dos eventos sobre o qual podemos obter dados quantitativos são necessariamente limitados e podem não incluir os mais importantes para uma análise correta. ${ }^{51}$

Enquanto na física assume-se, provavelmente com razão, que qualquer fator importante que determina os eventos observados será ele próprio diretamente observável e mensurável, no estudo de fenômenos complexos como o mercado, que dependem das ações de muitos indivíduos, todas as circunstâncias que irão determinar o resultado de um processo, dificilmente serão totalmente conhecidas ou mensuráveis.

A título de exemplo, Hayek analisa um jogo de bola em que participam pessoas com aproximadamente as mesmas habilidades. Se o estudioso tivesse acesso a fatos particulares, além do conhecimento geral, tais como estado de atenção, percepções, provavelmente poderia prever o resultado. Mas nossa capacidade de prever será limitada a tais características gerais dos eventos que se espera e não incluem a capacidade de prever eventos individuais particulares.

Assentadas estas bases, Hurwicz, em 1960, observou a questão dos incentivos para comunicação informativa e introduziu o conceito geral de mecanismo, como sendo um sistema de comunicação em que os participantes trocam mensagens uns com os outros de forma a determinar uma escolha social. O mecanismo age como um computador central que compila e processa as informações disponíveis, recomendando uma ação a

51HAYEK, Friedrich August von. - Prize Lecture: The Pretence of Knowledge".

Nobelprize.org. Nobel Media AB 2014.

$<$ http://www.nobelprize.org/nobel_prizes/economic-sciences/laureates/1974/hayeklecture.html>. Acesso em: 03 ago. 2016. 


\section{Revista da Faculdade Mineira de Direito $\mid$ v.20 N.40|233}

partir do conjunto de informações recebido, conforme um conjunto préespecificado de regras que mapeiam mensagens em escolhas. ${ }^{52}$

Ao proceder desta forma, deu um longo passo à frente de Hayek na análise de problemas fundamentais das instituições, abrindo espaço para pesquisas de campo, que foram desenvolvidas por Harsanyi em 1967, com o modelo Bayesiano de jogos. ${ }^{53}$

Em 1972, Hurwicz tornou a teoria relevante na prática com a publicação de mais um artigo que considerou os incentivos dos participantes incorporados na forma denominada compatibilidade de incentivos. Esta análise lhe permitiu concluir que os agentes apenas revelam suas informações privadas quando lhes convem, ou seja, quando há incentivos apropriados para este fim. ${ }^{54}$

Trata-se de uma teoria que conjuga os mecanismos necessários para que os agentes sejam corretamente incentivados a revelar as informações privadas ao agente central. A dificuldade está, evidentemente, em determinar o desenho institucional ótimo, apto a alocar de forma eficiente os recursos.

Myerson afirma que nos mercados e nas outras instituições da sociedade as ações individuais dependem de outras informações que são disponibilizadas. Esta é a perspectiva recomendada por Hayek, a respeito da necessidade de que as instituições sociais sejam compreendidas como mecanismos de recebimento de informações e coordenação das ações das pessoas. Assim, uma boa instituição social é aquela que desempenha este papel de comunicação e coordenação. ${ }^{55}$

Para que o desenho funcione, é preciso, como já mencionado, que sejam estabelecidos os incentivos apropriados para que os agentes

52Desenho de Mecanismo. Disponível em:

$<\underline{\text { http:/ / epge.fgv.br/we/MD/TeoriaMicroeconomicaIV } / 2010 \text { ?action=AttachFile\&do }=g}$ et\&target $=$ aula06.pdf. $>$ Acesso em: 30 jul. 2016.

53MYERSON, Roger B - Prize Lecture: Perspectives on Mechanism Design in Economic Theory", p. 321.

54MYERSON, Roger B - Prize Lecture: Perspectives on Mechanism Design in

Economic Theory", p. 322.

55Idem. 


\section{Revista da Faculdade Mineira de Direito $\mid$ v.20 N.40|234}

revelem, com honestidade, as informações e obedeçam aos comandos da instituição social.

Conforme destaca Leonid Hurwicz, os mecanismos devem permitir o cumprimento das regras pelos próprios agentes, simplificando a supervisão sobre as instituições, na medida em que estas representam custos. A ideia é de evitar a existência de uma regressão infinita do que ele denomina "guardiões", pois isso nem sempre é possível, uma vez que aumentaria os custos de transação. ${ }^{56}$

Assim, os mecanismos devem se traduzir em normas auto aplicáveis (self-enforcemnet), na medida em que os ganhos obtidos com a utilização de estratégias lícitas tornam menos atrativas as estratégias ilícitas. Para Hurwicz, uma formulação auto aplicável é aquela capaz de mostrar para os agentes que para cada estratégia ilícita existe uma estratégia lícita que é mais atrativa, pois gerará ganhos superiores. ${ }^{57}$

A questão da revelação honesta da informação relaciona-se à seleção adversa (adverse selection) e da obediência aos comandos institucionais ao perigo moral (moral hazard). Havendo o equilíbrio, podese dizer que há uma compatibilidade de incentivos (the plan is incentive compatible). ${ }^{58}$

Associada à seleção adversa e ao perigo moral, Mayerson estabelece a necessidade de descrever ao mediador como deverá ser implementado o plano da compatibilidade de incentivos. Quando as informações privadas são confiadas ao mediador, é preciso computar os relatórios desonestos. Do mesmo modo, ao prever as recomendações, é preciso computar os comportamentos desviantes. Agindo desta forma, o mediador alcançará o equilíbrio e finalmente recomendará de forma confidencial as ações de cada indivíduo para que o resultado ótimo seja atingido.

56HURWICZ, Leonid. Prize Lecture: But Who Will Guard The Guardians?.

Nobelprize.org. Nobel Media AB 2014. Web. 3 Aug. 2016.

<http://www.nobelprize.org/nobel_prizes/economic-

sciences/laureates/2007/hurwicz_lecture.pdf.>, p. 286.

57Idem, p. 285.

58MYERSON, Roger B - Prize Lecture: Perspectives on Mechanism Design in

Economic Theory, p. 323. 


\section{Revista da Faculdade Mineira de Direito | v.20 N.40|235}

Após este processo, se algum indivíduo tinha qualquer incentivo para ser desobediente em relação ao mediador no âmbito do plano, ele teria tido um incentivo também para ser desonesto ou desobedientes a si mesmo sob a estratégia de equilíbrio do mecanismo dado. Mas, num equilíbrio racional ninguém pode ganhar mentindo para si mesmo ou desobedecer a sua própria estratégia ideal. ${ }^{59}$

Vale dizer, a teoria não descarta a possibilidade de desonestidade e desobediência. Mas o diferencial do modelo é que em um desenho ótimo, o agente que agir de forma desonesta ou desobediente será também prejudicado. Dado este incentivo, o agir oportunista se torna desinteressante.

Um exemplo da aplicação da teoria é a de uma mãe (no caso, mediadora ou instituição social) que precisa dividir um pedaço de bolo entre seus dois filhos (a) e (b). Nesta hipótese, para evitar futuras arguições de desfavorecimento, ela questiona se ambos querem um pedaço do bolo. Após receber as informações, ela recomenda que o filho (a) corte o bolo em dois pedaços e o filho (b) escolha primeiro. Assim, ambos os filhos são incentivados a fornecer a informação honesta, de que querem o bolo e o filho (a) é incentivado a cortar o bolo em pedaços iguais, haja vista que se não o fizer, poderá ficar com o pedaço menor, já que ficou garantida a escolha prioritária ao outro irmão. ${ }^{60}$

A teoria teve seu auge em 1994, quando a Comissão Federal de Comunicações dos Estados Unidos aplicou a teoria na área de comunicações, passando o sistema de loterias de licenças para faixas de frequência de telefonia móvel por leilões, gerando uma receita de 20 bilhões de dólares ao governo. A revista Fortune considerou o mecanismo como o mais dramático exemplo do novo poder da teoria dos jogos e o

\footnotetext{
59Idem, p. 324.

60BUGARIN, Mauricio S. O que é desenho de mencanismos e qual a importância de seu estudo? Disponível em: <http://www.brasil-economiagoverno.org.br/2012/09/24/o-que-e-desenho-de-mecanismos-e-qual-a-importancia-deseu-estudo/>. Acesso em: 30 jul. 2016.
} 


\section{Revista da Faculdade Mineira de Direito | v.20 N.40|236}

modelo foi copiado em 2000, gerando uma receita de 34 bilhões de dólares ao governo britânico. ${ }^{61}$

O sucesso da teoria aplicada em diversos setores da economia tem sido comprovado ao longo dos anos e, por este motivo, acredita-se na possibilidade de que o desenho de mecanismos seja uma alternativa viável ao preenchimento das lacunas dos contratos, quando aplicado ao Poder Judiciário, conforme será analisado adiante.

\subsection{Aplicação aos casos submetidos ao Poder Judiciário}

Scott e Triantis consideram que um dos problemas relacionados ao Poder Judiciário está no fato que em certos casos a alocação eficiente dos recursos é visualizada pelas partes, mas não pela Corte. ${ }^{62}$

Um exemplo seria da situação em que (a) e (b) pretendem a extinção do condomínio de um imóvel comum. Trata-se de um imóvel familiar e (a) e (b) têm preferência sobre uma área pré-determinada. A Corte solicita o envio das informações a respeito dos desejos das partes e ambas informaram seu interesse na divisão, bem como na respectiva área correspondente à pretensão. Na sequência, a Corte ordena a divisão na forma indicada e a alocação dos recursos é ótima. Se houver divergência nas informações, (a) e (b) seriam penalizados com o prolongamento excessivo da demanda, envolvendo tempo e custo e com a impossibilidade de usufruir do bem objeto da divisão.

Além disso, o objetivo da Corte é de alcançar a verdade para promover a justiça. Todavia, se as informações disponíveis estiverem incorretas, o risco de uma decisão injusta e desfavorável à eficiência é alto, aumentando os custos de transação.

Por estes motivos, Scott e Triantis entendem que o processo judicial deve ser compreendido como um fator endógeno ao contrato e, inclusive, ser computado como um custo de transação ex post. ${ }^{63}$ Os riscos

\footnotetext{
61BUGARIN, Mauricio S. O que é desenho de mencanismos e qual a importância de seu estudo?. Acesso em: 30 jul. 2016.

62SCOTT, Robert E.; TRIANTIS, George G. Incomplete Contracts and the Theory of Contract Design, , p. 195.

63Idem, p. 201.
} 


\section{Revista da Faculdade Mineira de Direito $\mid$ v.20 N.40 237}

da alocação deficiente de recursos devem ser considerados para que o contrato desenhe uma estrutura de mecanismos ótima em termos de incentivos dos agentes no âmbito do Poder Judiciário.

Ao celebrar o contrato as partes precisam analisar os custos do litígio e a probabilidade de ver seu direito garantido ao final. Neste momento é feita uma previsão do investimento necessário ao litígio em termos de acesso, produção de provas e cumprimento de eventual decisão judicial associado ao tempo de duração do processo. Se os custos forem inferiores à renda obtida, o contrato será celebrado.

No Brasil, dada a insegurança jurídica já comentada neste estudo, os custos inviabilizariam, em muitos casos, a celebração do contrato. A considerada justiça lotérica é incapaz de fornecer ex ante aos agentes contratantes uma previsão de como será resolvida eventual contingência.

Em virtude deste cenário é que se propõe a aplicação da teoria do desenho de mecanismos nas disputas contratuais levadas ao conhecimento do Poder Judiciário.

Scott e Triantis sugerem que os contratantes estruturem o contrato no sentido de fornecer incentivos às partes durante o litígio, em termos de procedimento e produção de provas, nos limites permitidos pela lei.

Cooter e Ullen consideram as informações uma parte importante do fomento de compromisso e cooperação entre as partes contratuais. Antes de firmarem o contrato, as partes têm conhecido privado sobre o que esperam conseguir com o negócio, assim como o preço que estão dispostas a pagar e receber e as obrigações a que estão dispostas a se comprometer. ${ }^{64}$

Além disso, é possível que uma das partes possua uma informação que a outra não possua, como por exemplo, o potencial de valorização de um imóvel. Trata-se de uma situação de informação assimétrica. ${ }^{65}$

O Direito, segundo os autores, pode auxiliar as partes privadas a lidar com informações assimétricas ao criar regras de formação e execução que orientem as partes sobre informações que terão obrigação de divulgar

64COOTER, Robert; ULLEN, Thomas. Direito e Economia. p. 213.

65Idem. 


\section{Revista da Faculdade Mineira de Direito $\mid$ v.20 N.40|238}

e quais podem ser guardadas. Em virtude disso, o Direito pode ser utilizado para incentivar a revelação eficiente de informações dentro da relação contratual. ${ }^{66}$

Havendo a necessidade de recorrer ao Poder Judiciário, o mesmo desenho pode ser feito. Em um primeiro momento, o objetivo seria obter uma solução do conflito em sede preliminar, mediante a informação pelas partes ao Juiz, do que entenderiam por uma solução apta a satisfazer sua pretensão. O Juiz mediador representando o Poder Judicial, como instituição social, receberia as comunicações das partes e, com base no conjunto de regras em vigor, analisaria eventual desonestidade e desobediência futura para fazer suas recomendações.

Existindo, como se espera, a comunicação honesta de informação, a alocação dos recursos seria ótima. Por outro lado, na hipótese de desonestidade por uma das partes, o Juiz poderia onerá-la com o ônus da prova e o pagamento das custas processuais. E para coibir a desobediência ao comando, o Juiz poderia, também, fixar penalidades.

A título de exemplo, tome-se os processos de indenização por dano moral. Em que pese a mudança de posicionamento do Poder Judiciário ao reconhecer que o mero dissabor não configura dano moral, a procura por indenizações ainda está entre as maiores causas de litígio tanto no âmbito do Direito Civil como do Direito do Consumidor, conforme informa o Gráfico 4.50, que expõe os assuntos mais demandados na Justiça Estadual, do Relatório Justiça em Números 2015, elaborado pelo Conselho Nacional de Justiça. ${ }^{67}$

$\mathrm{Na}$ Justiça Estadual o gráfico demonstra que no ano-base de 2014 cerca de 3.219.798 (três milhões e duzentos e dezenove mil e setecentos e noventa e oito) processos foram ajuizados em primeiro e segundo grau de jurisdição. $^{68}$

Os litigantes destes processos estão imbuídos, em grande parte, da premissa de "o que vier é lucro" e, em grande parte, recebem mais do que esperavam. Ora, se o Autor recebeu uma indenização de $\mathrm{R} \$ 10.000,00$ (dez

66Idem.

67Justiça em números 2015: ano-base 2014/Conselho Nacional de Justiça - Brasília:

CNJ, 2015, p. 98.

68Idem. 


\section{Revista da Faculdade Mineira de Direito | v.20 N.40|239}

mil reais) mas ficaria satisfeito com $\mathrm{R} \$ 5.000,00$ (cinco mil reais) o desenho de mecanismos poderia conduzir à uma alocação eficiente. Se as partes comunicam inicialmente e de forma confidencial ao Juiz quando o Réu pode pagar e quanto o Autor aceita receber, a solução ótima tem mais chances de ser alcançada.

As pessoas respondem à incentivos e por isso é que resultados eficientes podem ser alcançados quando estabelecidos os estímulos adequados. Conforme destaca Ivo Gico Jr., o agente econômico pondera custos e benefícios das alternativas disponíveis, adotando a conduta que lhe traz mais bem-estar. ${ }^{69}$ Trata-se da conduta racional maximizadora, dadas as limitações inerentes à racionalidade do agente. ${ }^{70}$

Conscientes de que se a comunicação inicial ao Juízo for honesta e as recomendações forem atendidas na forma determinada o resultado será o melhor para as partes e o comportamento desviante será evitado. Do contrário, havendo a comunicação de informações equivocadas, o equilíbrio será alterado e a parte que agiu com desonestidade também perderá.

\section{Conclusão}

Conforme exposto em sede introdutória, o comportamento humano deve ser levado em consideração no ajuste de compromissos empresariais. A complexidade derivada da interação humana, o oportunismo e o agir ilícito são fatores endógenos ao contrato, que devem ser computados na previsão dos custos de transação.

A aplicação da teoria do desenho de mecanismos como forma de preencher as lacunas dos contratos incompletos e dirigir litígios é uma das hipóteses de solução ao problema, que se apresenta, ab initio, com baixos custos transacionais.

69GICO JUNIOR, Ivo Teixeira. Introdução à Análise Econômica do Direito. In: RIBEIRO, Marcia Carla Pereira; KLEIN, Vinicius (Coords.). O que é análise econômica do direito: uma introdução. Belo Horizonte: Fórum, 2011. p. 22. 70RIBEIRO, Marcia Carla Pereira. Racionalidade Limitada. Introdução à Análise Econômica do Direito; KLEIN, Vinicius (Coords.). O que é análise econômica do direito: uma introdução. Belo Horizonte: Fórum, 2011. p. 66. 


\section{Revista da Faculdade Mineira de Direito $\mid$ v.20 N.40|240}

Isto porque, conforme exposto neste artigo, os incentivos devem ser desenhados de forma a garantir que as estratégias legais sejam sempre mais atrativas do que o comportamento oportunista. Deste modo, ao agir de forma desonesta, o próprio agente será prejudicado, o que torna o mecanismo autoaplicável e, via de consequência, de baixos custos de implementação.

Outro aspecto interessante da teoria é o de que os agentes participam do desenho na formulação do contrato inicial. Vale dizer: participam da elaboração das regras do jogo, o que pode evitar futuras alegações de que foi injustamente coagido ou prejudicado. Ao mesmo tempo, este mecanismo faz com que os agentes ajustem apenas obrigações que têm interesse em cumprir, pois o descumprimento será, de igual modo, desvantajoso.

Trata-se de uma proposta de solução aos problemas de eficiência dos contratos à qual podem ter acesso pesquisadores e práticos voltados aos contratos, especialmente aos contratos empresariais de longo prazo, a fim de corroborarem com a proposta teórica desenvolvida no artigo, especialmente agora que o Novo Código de Processo Civil consagra a possibilidade de serem firmados negócios judiciais com vistas a tornar-se a prestação judicial mais célere e eficiente. Nada impede que tais negócios, como por exemplo delimitar as alternativas recursais, sob pena de imposição de pesadas multas na hipótese de abuso de direito ou de comportamento oportunista de uma parte ter sido revelado em juízo, seja prefixado já na elaboração do contrato.

\section{Referências}

ARAÚJO, Fernando. Teoria econômica do contrato. Coimbra: Almedina, 2007.

BEINHOCKER, Eric D. The Origin of Wealth. Evolution, complexity, and the radical remaking of economics. Harvard Business School Press, Boston, Massachussets, 2006.

BELlANTUONO, Giuseppe. Analisi economica del diritto. Trento: 


\section{Revista da Faculdade Mineira de Direito $\mid$ v.20 N.40 $\mid 241$}

Uni-service, 2005.

BUGARIN, Mauricio S. O que é desenho de mencanismos e qual a importância de seu estudo? Disponível em: <http://www.brasileconomia-governo.org.br/2012/09/24/o-que-e-desenho-de-mecanismose-qual-a-importancia-de-seu-estudo/>. Acesso em: 30 jul. 2016.

CAMINHA, Uinie; LIMA, Juliana Cardoso. Contrato Incompleto: uma perspectiva entre direito e economia para contratos de longo termo. Revista Direito GV. São Paulo 10 (1), p. 155-200, Jn-jun. 2014.

COASE, Ronald. H. O problema do custo social. In: The Latin American and Caribbean Journal of Legal Studies, Vol. 3, Issue 1, Article 9, University of Chicago, 2008.

COASE, Ronald H. (1964), 'The Regulated Industries: Discussion', 54 American Economic Review, 194-197.

COOTER, Robert; ULLEN, Thomas. Direito e Economia. Tradução Luis Marcos Sander e Francisco Araújo Costa. 5. ed. Porto Alegre: Bookman, 2010. p. 213.

DAVIS, Lance E.; NORTH, Douglass C. (1971), Institutional Change and American Economic Growth, Cambridge, Cambridge University Press.

Desenho de Mecanismo. Disponível em: <http://epge.fgv.br/we/MD/TeoriaMicroeconomicaIV/2010?action=At tachFile\&do=get\&target=aula06.pdf. $>$ Acesso em: 30 jul. 2016.

GICO JUNIOR, Ivo Teixeira. Introdução à Análise Econômica do Direito. In: RIBEIRO, Marcia Carla Pereira; KLEIN, Vinicius (Coords.). O que é análise econômica do direito: uma introdução. Belo Horizonte: Fórum, 2011. 


\section{Revista da Faculdade Mineira de Direito $\mid$ v.20 N.40|242}

HAYEK, Friedrich August von. - Prize Lecture: The Pretence of Knowledge". Nobelprize.org. Nobel Media AB 2014. <http://www.nobelprize.org/nobel_prizes/economicsciences/laureates/1974/hayek-lecture.html>. Acesso em: 03 ago. 2016.

HURWICZ, Leonid. Prize Lecture: But Who Will Guard The Guardians?. Nobelprize.org. Nobel Media AB 2014. Web. 3 Aug. 2016. <http://www.nobelprize.org/nobel_prizes/economicsciences/laureates/2007/hurwicz_lecture.pdf.>.

Justiça em números 2015: ano-base 2014/Conselho Nacional de Justiça - Brasília: CNJ, 2015, p. 98.

KLEIN, Peter G. New Institucional Economics. Department of Economics, University of Georgia, 1999.

MARASCO, Gherardo. La rinegoziazione del contratto - Strumenti legali e convenzionale a tutela dell'equilibrio negoziale. [S. 1.]: Cedam, 2006.

NORTH, Douglass C. Economic Performance Through Time. Nobelprize.org. Nobel Media AB 2014. Web. 11 Oct. 2014. Disponível em: <http://www.nobelprize.org/nobel_prizes/economicsciences/laureates/1993/north-lecture.html>. Acesso em: 15 jul. 2016.

PINHEIRO, Armando Castelar. Segurança jurídica, crescimento e exportações. Disponível em: <www.ipea.gov.br/ pub/td/2005/td_1125.pdf $>$. Acesso em: 30 jul. 2016.

PINHEIRO, Armando Castelar; SADDI, Jairo. Direito, economia e mercados. Rio de Janeiro: Elsevier, 2005.

REZENDE, Christiane Leles Rezende; ZYLBERSZTAJN, Decio. Quebras contratuais e dispersão de sentenças. Revista Direito GV. São Paulo 7 (1), p. 155-176, Jan-Jul 2011. 


\section{Revista da Faculdade Mineira de Direito $\mid$ v.20 N.40|243}

RIBEIRO, Marcia Carla Pereira. Racionalidade Limitada. Introdução à Análise Econômica do Direito; KLEIN, Vinicius (Coords.). O que é análise econômica do direito: uma introdução. Belo Horizonte: Fórum, 2011.

ROCHA, Lara Bonemer Azevedo da. O desenvolvimento pelo acesso à justiça. São Paulo: Boreal, 2015.

MYERSON, Roger B. - Prize Lecture: Perspectives on Mechanism Design in Economic Theory". Nobelprize.org. Nobel Media AB 2014. Web. 3 Aug 2016. <http://www.nobelprize.org/nobel_prizes/economicsciences/laureates/2007/myerson-lecture.html>, p. 321.

SCOTT, Robert E. TRIANTIS, George G.. Incomplete Contracts and the Theory of Contract Design, 56 Case Western Reserve Law Review. 187 (2005) Disponível em: http://scholarlycommons.law.case.edu/caselrev/vol56/iss1/9 Acesso em 15 jul. 2016, p. 190.

SZTAJN, Rachel; ZYLBERSZTAJN, Decio. Direito e economia: análise econômica do direito e das organizações. Rio de Janeiro: Campus, 2005, p. 3.

SZTAJN, Rachel. Supply chain e incompletude contratual. Disponível em:

<http://www.revistassystemas.com.br/index.php/systemas/article/viewP DFInterstitial/10/11>. Acesso em: 01 ago.2016.

WILLIAMSON, Oliver E. The Economic Institutions of Capitalism. New York: The Free Press, 1985. 
Revista da Faculdade Mineira de Direito | v.20 N.40 244 